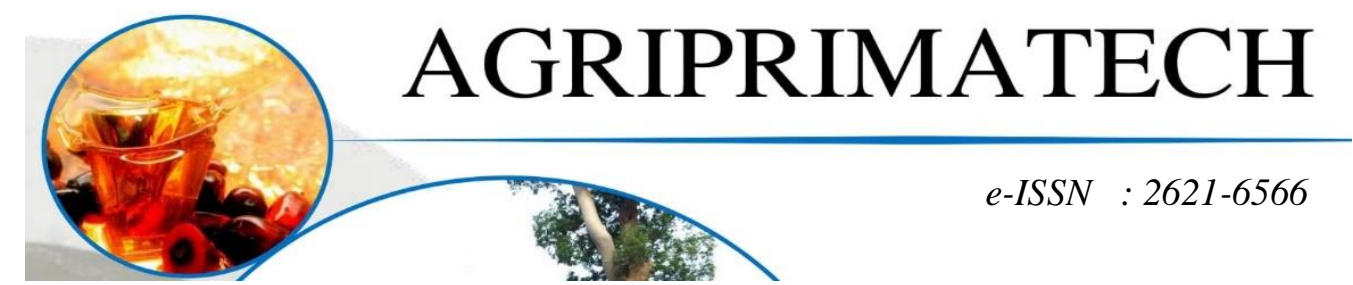

\title{
ANALISIS FAKTOR-FAKTOR YANG MEMPENGARUHI PENDAPATAN USAHATANI JAGUNG \\ (Nagori Bayu Bagasan Kecamatan Tanah Jawa Kabupaten Simalungun)
}

\author{
ROMAULI SIMANJUNTAK ${ }^{1}$, MARTUA SIADARI ${ }^{2}$, NUR HALIMAH DAMANIK ${ }^{3}$ \\ 1,2 Dosen Program Studi Agribisnis Fakultas Pertanian Universitas Simalungun \\ ${ }^{3}$ Mahasiswa Program Studi Agribisnis Fakultas Pertanian Universitas Simalungun \\ Email: romaulisimanjuntak@yahoo.com
}

\begin{abstract}
ABSTRAK
Penelitian ini bertujuan untuk mengetahui besarnya pendapatan dan mengetahui faktor-faktor yang mempengaruhi pendapatan usahatani jagung di Nagori Bayu Bagasan. Penelitian ini dilakukan di Nagori Bayu Bagasan Kecamatan Tanah Jawa Kabupaten Simalungun dengan melibatkan 30 responden. Data yang digunakan dalam penelitian ini adalah data primer dan data sekunder. Model analisis yang digunakan R/C dan analisis regresi linear berganda. Hasil uji-t menunjukan bahwa variabel luas lahan dan modal tidak berpengaruh nyata terhadap pendapatan usahatani jagung di Nagori Bayu Bagasan dengan nilai sig $>0,050$. Sedangkan untuk variabel tenaga kerja dan produksi berpengaruh nyata terhadap pendapatan usahatani jagung di Nagori Bayu Bagasan dengan nilai sig $<0,050$. Hasil analisis dapat diketahui bahwa rata-rata produksi per usahatani Rp $1.873 \mathrm{~kg}$ jagung dengan harga jual rata-rata per usahatani Rp 3.556,67 sehingga didapatkan rata-rata penerimaan per usahatani sebesar $\mathrm{Rp}$ 6.687.183,33. Dengan demikian pendapatan usahatani jagung per usahatani sebesar Rp 3.623.146,93 dan rata-rata per Ha yaitu $\mathrm{Rp} 11.275 .353,53$. R/C dari hasil penelitian adalah 2,15 .
\end{abstract}

Kata Kunci : Jagung, Pendapatan, Usahatani, Analisis

\section{PENDAHULUAN}

Indonesia merupakan negara pertanian, artinya sektor pertanian dalam tatanan pembangunan nasional memegang peranan penting, karena selain bertujuan menyediakan pangan bagi seluruh penduduk, pertanian juga merupakan sektor andalan penyumbang devisa negara dari sektor non migas. Besarnya kesempatan kerja yang diserap dan besarnya jumlah penduduk yang masih bergantung pada sektor ini memberikan arti bahwa dimasa mendatang sektor ini masih perlu ditingkatkan (Soekartawi, 1995).

Jagung merupakan salah satu tanaman yang banyak ditanam di setiap Negara, termasuk Indonesia. Jagung adalah sumber pangan kedua setelah padi. Hampir $70 \%$ hasil produksi jagung ini dimanfaatkan untuk konsumsi dan sisanya untuk berbagai keperluan, baik sebagai pakan ternak, kebutuhan permintaan pasar, maupun kebutuhan industri. 
Tujuan dari penelitian yaitu untuk menganalisis faktor-faktor apa saja yang mempengaruhi produksi usahatani jagung dan untuk menganalisis faktorfaktor apa saja yang mempengaruhi pendapatan usahatani jagung di Nagori Bayu Bagasan Kecamatan Tanah Jawa Kabupaten Simalungun.

\section{METODE PENELITIAN}

Penelitian ini dilaksanakan di Nagori Bayu Bagasan Kecamatan Tanah Jawa Kabupaten Simalungun dengan alasan karena sebagian masyarakat di sana membudidayakan tanaman jagung. Waktu penelitian dilaksanakan pada bulan Januari Februari 2020. Jumlah sampel dalam penelitian ini adalah 30 orang.

Metode yang digunakan dalam pengambilan sampel adalah proportional random sampling (sampel acak berimbang). Dengan Rumus hipotesis I digunakan analisis rasio R/C dengan rumus:

$$
R / C=T R / T C
$$

Dimana :

$\mathrm{TR}=$ Total Revenew

$\mathrm{TC}=$ Total Cost

Dengan kaidah keputusan :

$\mathrm{R} / \mathrm{C}<1 \quad$ : Maka usahatani rugi

$\mathrm{R} / \mathrm{C}=1$ : Usahatani impas

$1<\mathrm{R} / \mathrm{C}<2$ :Usahatani menguntungkan tapi belum layak dikembangkan

$\mathrm{R} / \mathrm{C} \geq 2 \quad$ :Usahatani menguntungkan dan layak dikembangkan.

Untuk hipotesis II digunakan analisis regresi linier berganda dengan rumus sebagai berikut :

Dimana :

$$
Y=a+b_{1} X_{1}+b_{2} X_{2}+b_{3} X_{3}+b_{4} X_{4}
$$

$$
\begin{array}{ll}
\mathrm{Y} & =\text { Pendapatan }(\mathrm{Rp}) \\
\mathrm{a} & =\text { Konstanta } \\
\mathrm{b}_{1}+. .+\mathrm{b}_{4}=\text { Koefisien } \\
\mathrm{X}_{1} \quad=\text { Luas lahan }(\mathrm{Ha}) \\
\mathrm{X}_{2} \quad=\text { Tenaga Kerja (HOK) } \\
\mathrm{X}_{3} \quad=\text { Modal (Rp) } \\
\mathrm{X}_{4} & =\text { Produksi }(\mathrm{Kg})
\end{array}
$$

\section{HASIL DAN PEMBAHASAN}

\section{Analisis Budidaya Usahatani Jagung di Nagori Bayu Bagasan} Kegiatan usahatani jagung di Nagori Bayu Bagasan Kecamatan Tanah Jawa Kabupaten Simalungun dimulai dari :

\section{$>$ Pengolahan Lahan}

Di Nagori Bayu Bagasan pengolahan lahan dilakukan $2 x$ per musim tanam dengan tujuan agar pertumbuhan jagung baik. Pengolahan lahan dilakukan menggunakan traktor.

\section{Penanaman}

Penanaman jagung dilakukan saat hujan tiba, baru keesokan harinya petani menanam jagung. Alasan ditunggunya hujan saat menanam jagung adalah agar persentase tumbuhnya tinggi sekitar $95 \%$.

\section{Pemeliharaan}

Di Nagori Bayu Bagasan pemeliharaan jagung dilakukan dengan 2 cara yaitu penyiangan gulma dan penyemprotan herbisisda (untuk mengendalikan gulma).

\section{$>$ Pemupukan}

Di Nagori Bayu Bagasan pemupukan jagung dilakukan dengan cara pupuk tabur di dekat jagung.

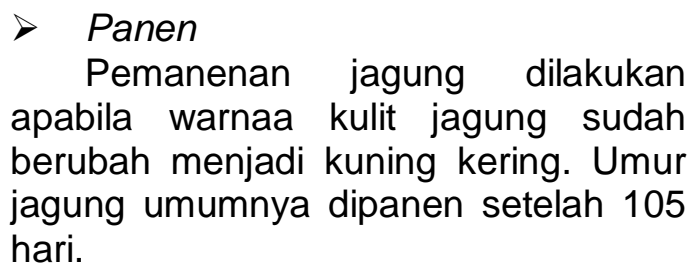
apabila warnaa kulit jagung sudah berubah menjadi kuning kering. Umur jagung umumnya dipanen setelah 105 hari. 
Tabel 1. Biaya Penggunaan Sarana Produksi Usahatani Jagung Per Musim Tanam Tahun 2020

\begin{tabular}{|c|c|c|c|}
\hline No & Uraian & $\begin{array}{l}\text { Rata-rata Biaya } \\
\text { per Usahatani } \\
\text { (Rp) }\end{array}$ & $\begin{array}{c}\text { Rata- } \\
\text { rata } \\
\text { Biaya } \\
\text { per Ha } \\
(\mathrm{Rp})\end{array}$ \\
\hline 1 & Organik & $13.333,33$ & $\begin{array}{l}41.493 \\
, 78\end{array}$ \\
\hline 2 & Dolomit & $34.166,67$ & $\begin{array}{l}106.32 \\
7,80\end{array}$ \\
\hline 3 & Urea & $199.333,33$ & $\begin{array}{l}620.33 \\
1,95\end{array}$ \\
\hline 4 & SP36 & $136.166,67$ & $\begin{array}{l}423.75 \\
5,19\end{array}$ \\
\hline 5 & Phonska & $159.000,00$ & $\begin{array}{l}494.81 \\
3,28\end{array}$ \\
\hline 6 & Gramoxone & $15.750,00$ & $\begin{array}{l}49.014 \\
, 52\end{array}$ \\
\hline 7 & Clariss & $135.333,33$ & $\begin{array}{l}421.16 \\
1,83\end{array}$ \\
\hline 8 & Bibit Jagung & $426.000,00$ & $\begin{array}{l}1.325 \\
726,14\end{array}$ \\
\hline & Jumlah & $1.119 .083,33$ & $\begin{array}{l}3.482 \\
624,48\end{array}$ \\
\hline
\end{tabular}

Sumber : Data Primer Diolah, 2020

Dilihat dari tabel 1 menunjukkan bahwa total jumlah biaya sarana produksi per usahatani yaitu Rp.1.119.083,33 dengan rata-rata per $\mathrm{Ha}$ adalah $\mathrm{Rp} 3.482 .624,48$. usahatani jagung yang dilakukan oleh petani di Nagori Bayu Bagasan, Kabupaten Simalungun per musim tanam jika dirata-ratakan per $\mathrm{Ha}$ alan memerlukan bibit jagung sebanyak 21,06 per $\mathrm{Ha}$. Pupuk Urea sebanyak $308,61 \mathrm{~kg} / \mathrm{Ha}$, dan per usahatani sebanyak $99,17 \mathrm{~kg}$, pupuk organik sebanyak $51,87 \mathrm{~kg} / \mathrm{Ha}$ dan per usahatani sebanyak $16,67 \mathrm{~kg}$, dolomite sebanyak $212,66 \mathrm{~kg} / \mathrm{Ha}$ untuk rata-rata per usahatani $68,83 \mathrm{~kg}$, pupuk SP36 sebanyak $171,16 \mathrm{~kg} / \mathrm{Ha}$ dan per usahatani sebanyak $55 \mathrm{~kg}$, pupuk phonska sebanyak $176,35 \mathrm{~kg} / \mathrm{Ha}$ dan per usahatani sebanyak 56,67. Penggunaan pestisida gramoxone sebanyak 0,83 $\mathrm{L}$ dan per usahatani 0,27 $\mathrm{L}$, pestisida Claris sebanyak $1,61 \mathrm{~L} / \mathrm{Ha}$ dan per usahatani sebanyak $0,52 \mathrm{~L}$.
Tabel 2. Biaya Tenaga Kerja Usahatani Jagung Per Musim Tanam Tahun 2020

\begin{tabular}{llcc}
\hline No & Uraian Kegiatan & $\begin{array}{c}\text { Rata-rata per } \\
\text { Usahatani } \\
\text { (Rp) }\end{array}$ & $\begin{array}{c}\text { Rata-rata } \\
\text { per Ha } \\
\text { (Rp) }\end{array}$ \\
\hline 1 & Pengolahan Lahan & 158.333 & 492.738 \\
2 & Penanaman & 174.666 & 543.568 \\
3 & Pemupukan & 133.333 & 414.937 \\
4 & Pemeliharaan & 48.000 & 149.377 \\
5 & Penyemprotan & 64.000 & 199.170 \\
6 & Pemanenan & 244.000 & 759.336 \\
& Jumlah & $\mathbf{8 2 2 . 3 3 3}$ & $\mathbf{1 . 5 5 9 . 1 2 8}$ \\
\hline
\end{tabular}

Sumber : Data Primer Diolah, 2020

Dilihat dari Tabel 2 dapat dijelaskan bahwa dalam proses budidaya jagung, untuk biaya tenaga kerja tertinggi ada pada kegiatan pemanenan dengan rata-rata biaya tenaga kerja per usahatani yaitu $\mathrm{Rp}$ 244.000,00 dan rata-rata per $\mathrm{Ha} \mathrm{Rp}$ $759.336,10$. Sementara itu untuk biaya tenaga kerja terendah ada pada kegiatan pemeliharaan dengan biaya per usahatani adalah $\mathrm{Rp}$ 48.000,00 dengan rata-rata per $\mathrm{Ha}$ yaitu $\mathrm{Rp}$ 149.377,59. jumlah pencurahan tenaga kerja yang tertinggi pada budidaya usahatani jagung adalah pada proses pemanenan yaitu dengan jumlah sebanyak 15,19 HOK/Ha. Sementara itu untuk yang terendah yaitu pada proses pemeliharaan, dimana tenaga kerja berjumlah 2,99 HOK/Ha.

Tabel 3. Biaya Penyusutan Alat Usahatani Jagung Tahun 2020

\begin{tabular}{clcc}
\hline No & Alat & $\begin{array}{c}\text { Rata-rata per } \\
\text { Usahatani (Rp) }\end{array}$ & $\begin{array}{c}\text { Rata-rata per } \\
\text { Ha (Rp) }\end{array}$ \\
\hline 1 & Cangkul & 17.998 & 56.011 \\
2 & Sprayer & 38.110 & 118.601 \\
3 & Ember & 11.933 & 37.136 \\
4 & Mesin Babat & 41.111 & 127.938 \\
5 & Babat & $5.184,67$ & $16.134,85$ \\
6 & Goni & 17.982 & 55.960 \\
& Jumlah & $\mathbf{1 3 2 . 3 1 9 , 7 3}$ & $\mathbf{4 1 1 . 7 8 3 , 4 0}$ \\
\hline
\end{tabular}

Sumber : Data Primer Diolah, 2020

Berdasarkan tabel 3 dapat terlihat bahwa penyusutan alat pada usahatani jagung yang tertinggi yaitu 
pada sprayer mesin babat dengan ratarata biaya per usahatani sekitar $\quad R p$ 41.111,03 dengan rata-rata per Ha yaitu Rp 127.938,90. Sementara itu, untuk biaya penyusutan alat yang terendah adalah pada babat dengan rata-rata biaya per usahatani yaitu Rp 5.184,67 dengan rata-rata per $\mathrm{Ha}$ adalah $\mathrm{Rp}$ $16.134,85$. Sehingga total jumlah biaya penyusutan alat per usahatani $\mathrm{Rp}$ 132.319,73 dengan jumlah rata-rata per Ha yaitu Rp 411.783,40. peralatan yang digunakan dalam usahatani jagung diatas maka penggunaan alat yang tertinggi yaitu pada cangkul dan ember dengan rata-rata per usahatani 2,67 unit dan rata-rata per $\mathrm{Ha} 8,30$ unit, sementara yang terendah yaitu pada alat mesin babat dengan rata-rata per usahatani yaitu 0,67 unit, dan rata-rata per $\mathrm{Ha} 1,97$ unit.

\begin{tabular}{|c|c|c|c|}
\hline abel & \multicolumn{3}{|c|}{$\begin{array}{l}\text { Usahatani Jagung Per Musim } \\
\text { Tanam Tahun } 2020\end{array}$} \\
\hline No & Uraian & $\begin{array}{l}\text { Rata-rata per } \\
\text { Usahatani } \\
\text { (Rp) }\end{array}$ & $\begin{array}{c}\text { Rata-rata } \\
\text { per Ha (Rp) }\end{array}$ \\
\hline 1 & Sarana Produksi & 1.119 .083 & 3.482 .624 \\
\hline 2 & Tenaga Kerja & 822.333 & 2.559 .128 \\
\hline 3 & Penyusutan Alat & 132.319 & 411.783 \\
\hline 4 & Pajak Lahan & 30.000 & 93.361 \\
\hline 5 & Sewa Lahan & 962.666 & 2.955 .850 \\
\hline & Jumlah & 3.064 .036 & 9.535 .382 \\
\hline
\end{tabular}

Sumber : Data Primer Diolah, 2020

Berdasarkan data pada tabel 4

telah terlihat bahwa biaya produksi pada budidaya jagung per musim yang tertinggi yaitu pada biaya sarana produksi dengan rata-rata per usahatani yaitu $\mathrm{Rp}$ 1.119.083,33 dengan biaya rata-rata per Ha yaitu $\mathrm{Rp}$ 3.482.624,48. Sementara itu untuk biaya produksi yang terendah adalah pada biaya pajak lahan dengan ratarata per usahatani yaitu $\mathrm{Rp} 30.000,00$ dan untuk rata-rata biaya per Ha yaitu Rp 93.361,00.

\section{Analisis Kelayakan Usahatani Jagung Di Nagori Bayu Bagasan}

Berdasarkan dari hasil penelitian yang dilakukan di Nagori Bayu Bagasan, maka diperoleh produksi, biaya, penerimaan, pendapatan dan R/C sebagai berikut.

Tabel 5.Produksi, Harga, Biaya, Penerimaan, Pendapatan, dan R/C Tahun 2020

\begin{tabular}{|c|c|c|c|}
\hline No & Uraian & $\begin{array}{l}\text { Rata-rata per } \\
\text { Usahatani } \\
\text { (Rp) }\end{array}$ & $\begin{array}{c}\text { Rata-rata } \\
\text { per Ha } \\
\text { (Rp) }\end{array}$ \\
\hline 1 & $\begin{array}{l}\text { Produksi Jagung } \\
\text { (Kg) }\end{array}$ & $1.873,00$ & 3.482 .000 \\
\hline 2 & $\begin{array}{l}\text { Sewa lahan } \\
\text { (Rp) }\end{array}$ & 962.666 & 2.955 .850 \\
\hline \multirow[t]{5}{*}{3} & Biaya (Rp) & & \\
\hline & $\begin{array}{l}\text { Sarana Produksi } \\
\text { Tenaga Kerja }\end{array}$ & $\begin{array}{l}1.119 .083 \\
822.333\end{array}$ & $\begin{array}{l}3.482 .624 \\
2.559 .128\end{array}$ \\
\hline & Penyusutan Alat & 132.319 & 411.783 \\
\hline & Pajak Lahan & 30.000 & 93.361 \\
\hline & $\begin{array}{l}\text { Jumlah Biaya } \\
\text { (Rp) }\end{array}$ & 3.064 .036 & 9.535.382 \\
\hline 4 & Penerimaan (Rp) & 6.687 .183 & 20.810 .736 \\
\hline \multirow[t]{2}{*}{5} & Pendapatan (Rp) & 3.623 .146 & 11.275 .353 \\
\hline & $\mathrm{R} / \mathrm{C}$ & 2,15 & 6,70 \\
\hline
\end{tabular}

bahwa analisis R/C usahatani jagung yaitu 2,15 yang didapatkan dari hasil rata-rata produksi per usahatani $R p$ $1.873 \mathrm{~kg}$ jagung dengan harga jual ratarata per usahatani $\mathrm{Rp} 3.556$ sehingga didapatkan rata-rata penerimaan per usahatani sebesar Rp 6.687.183. Dengan demikian pendapatan usahatani jagung per usahatani sebesar $\mathrm{Rp}$ 3.623.146 dan rata-rata per Ha yaitu Rp 11.275.353. R/C dari hasil penelitian adalah $2,15>2$ artinya setiap pengeluaran sebesar $\mathrm{Rp} 1$ akan memberikan penerimaan sebesar $\mathrm{Rp}$ 2,15 .

Berdasarkan dari hasil analisis penelitian di Nagori Bayu Bagasan, Kabupaten Simalungun diperoleh $\mathrm{R} / \mathrm{C}=$ 2,15 artinya bahwa $R / C$ tersebut $\geq 2$. Hal ini telah menunjukkan bahwa usahatani jagung di Nagori Bayu Bagasan 
menunguntungkan dan layak dikembangkan. Dan hal tersebut menunjukkan bahwa hipotesis 1 diterima yang menyatakan usahtani jagung di Nagori Bayu Bagasan, Kabupaten Simalungun menguntungkan dan layak untuk dikembangkan.

\section{Analisis Faktor-Faktor Yang Mempengaruhi Pendapatan Usahatani Jagung}

Faktor-faktor yang menjadi variabel bebas dalam penelitian usahatani jagung ini dalah luas lahan (Rante), tenaga kerja (HOK), modal (Rp) dan jumlah produksi $(\mathrm{Kg})$ dengan variabel terikatnya adalah pendapatan (Rp). Untuk menjelaskan variasi dari pengaruh seluruh variabel-variabel bebas terhadap variabel terikat maka dapat dilihat dari koefisisen determinasi. a. Luas lahan

Nilai thitung dari luas lahan (X1) adalah $-1,611$ dan nilai sig luas lahan $0,185>0,050$. Nilai sig $>0,050$, hal ini berarti luas lahan tidak berpengaruh nyata terhadap pendapatan usahatani jagung di Nagori Bayu Bagasan pada tingkat kepercayaan 95\%. Koefesien luas lahan memiliki hubungan berpengaruh negative (-) terhadap pendapatan, ini berarti bahwa dengan penambahan luas lahan sebesar satu satuan $(1 \mathrm{Ha})$ maka akan menurunkan pendapatan sebesar -2.236.166,986 dengan asumsi faktor lain adalah konstan. Hal ini berarti dengan penambahan luas lahan tidak mempengaruhi pendapatan.

\section{b. Tenaga Kerja (HOK)}

Nilai thitung dari tenaga kerja (X2) adalah $-4,121$ dan nilai sig tenaga kerja $0,000<0,050$. Oleh karena itu nilai sig $<$ 0.050 , hal ini berarti tenaga kerja berpengaruh sangat nyata terhadap pendapatan usahatani jagung di Nagori Bayu Bagasan dengan tingkat kepercayaan 95\%. Koefisien tenaga kerja memiliki hubungan berpengaruh negative (-) terhadap pendapatan, ini berarti bahwa dengan penambahan tenaga kerja sebesar satu satuan (HOK) maka akan menurunkan pendapatan sebesar -13.163,444.

\section{Modal (Rp)}

Nilai thitung dari modal $(\mathrm{X} 3)$ adalah 0,388 dan nilai sig modal $0,701>0,050$. Oleh karena itu nilai sig $>0.050$, hal ini berarti modal tidak berpengaruh nyata terhadap pendapatan usahatani jagung di Nagori Bayu Bagasan dengan tingkat kepercayaan 95\%. Koefesien modal memiliki hubungan berpengaruh positif (+) terhadap pendapatan, ini berarti penggunaan modal yang berlebih tidak mempengaruhi pendapatan petani.

\section{d. Produksi $(\mathrm{Kg})$}

Nilai thitung dari produksi (X4) adalah 7,869 dan nilai sig produksi $0,000<0,050$. Oleh karena itu nilai sig $<$ 0.050, hal ini berarti produksi berpengaruh sangat nyata terhadap pendapatan usahatani jagung di Nagori Bayu Bagasan dengan tingkat kepercayaan 95\%. Koefesien produksi memiliki hubungan berpengaruh positif (+) terhadap pendapatan, ini berarti bahwa dengan penambahan jumlah produksi sebesar satu satuan $(1 \mathrm{Kg})$ maka akan meningkatkan pendapatan sebesar Rp 368,040.

\section{KESIMPULAN}

1) Usahatani jagung di Nagori Bayu Bagasan Kecamatan Tanah Jawa Kabupaten Simalungun menguntungkan dan layak dikembangkan.

2) Faktor tenaga kerja dan produksi berpengaruh sangat nyata terhadap pendapatan usahatani jagung, sedangkan luas lahan dan modal tidak berpengaruh nyata terhadap 
Agriprimatech

Vol. 4 No. 1, Oktober 2020

pendapatan usahatani jagung di

Nagori Bayu Bagasan Kecamatan

Tanah Jawa Kabupaten

Simalungun.

\section{DAFTAR PUSTAKA}

AAK. 1993. Teknik Bercocok Tanam Jagung. Kansius Yogyakarta.

Fitri Hidayatul, 2015. Analisis Usahatani Jagung. Fakultas Pertanian Universitas Simalungun

Hermanto, F. 1991. IImu Usahatani.

Penebar Swadaya, Jakarta.

Hartono. 2006. Statistik Untuk Penelitian, Yogyakarta. Pustaka Pelajar. 